\title{
Improving Subnational Input-Output Analyses Using Regional Trade Data: A Case-Study and Comparison
}

\author{
Meng Jiang, ${ }^{\text {II }}$ Lin Liu, ${ }^{\text {II }}$ Paul Behrens, Tao Wang, Zhipeng Tang, Dingjiang Chen, Yadong Yu, Zijian Ren, \\ Shengjun Zhu, Arnold Tukker,* and Bing Zhu*
}

Cite This: Environ. Sci. Technol. 2020, 54, 12732-12741

Read Online

\section{ACCESS 1}

Џlll Metrics \& More

Article Recommendations

Supporting Information

ABSTRACT: Environmentally extended input-output analysis (EE-IO) is widely used for evaluating environmental performance (i.e., footprint) at a national level. Many studies have extended their analyses to the subnational level to guide regional policies. One promising method is to embed nationally disaggregated input-output tables, e.g., nesting a provincial level table, into a global multiregional input-output table. However, a widely used approach to environmental assessment generally disaggregates the trade structure at the national level to the provincial level using the same proportions (proportionality assumption). This means that the subnational spatial heterogeneities on international trade are not fully captured. By calculating the Chinese provincial material footprint (MF) based on two approaches-the proportionality

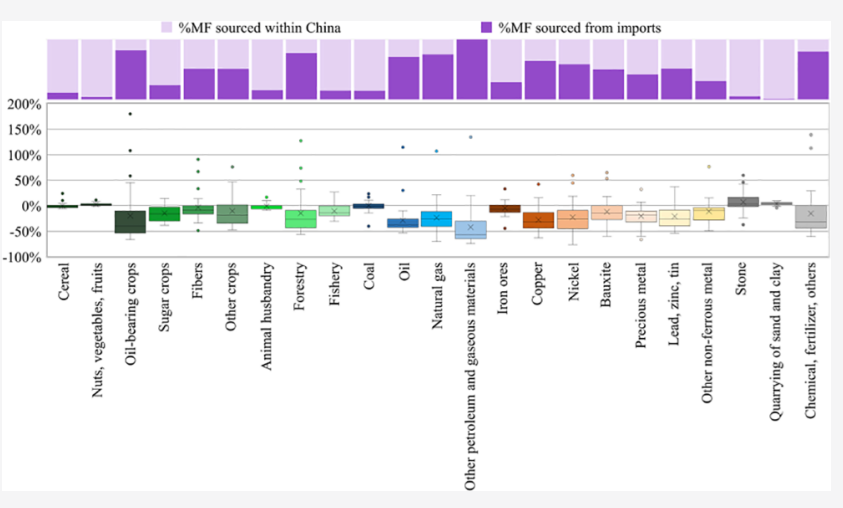
assumption and the actual customs statistics - in the same framework, we evaluate the quantitative differences when the proportionality assumption is addressed. By computing MF for 23 aggregated resources across 30 Chinese provinces, our results show for countries with large material flows like China, estimating subnational-level international trade by proportionality assumption may lead to significant differences in material flows at both the disaggregated and aggregated levels. An important follow-up question is whether these differences are also relevant for other footprints.

\section{INTRODUCTION}

Globalization has increased the geographical separation and supply chain complexity between production and consumption. ${ }^{1}$ Developed countries tend to outsource their material demand as well as environmental pressures to developing economies. $^{2-4}$ The increasing complexity involved in producing goods also drives the separation of production and consumption within large countries such as China., ${ }^{1,4-6}$ These separations are reflective of large inequalities between nations and between subnational regions. ${ }^{2,3}$ Environmentally extended input-output analysis (EE-IO) is an effective tool for assessing the patterns of production and consumption among regions, and for investigating the environmental pressures driven through global/regional supply chains. ${ }^{7-9}$ For example, EE-IO analyses are often used to perform footprinting assessments (also called consumption-based accounting, CBA), which provide a life cycle (consumption-based) perspective that supplements territorial, production-based accounting (PBA). ${ }^{8,10}$ This approach can be used to assess many environmental pressures, such as carbon emissions, water use, land use, material use, pollutions, and many others. ${ }^{1,4,11-16}$

EE-IO has been increasingly used to explore the subnational transfer of environmental impacts. ${ }^{17}$ Large regional disparities within nations that become even more important when we consider that a single subnational region in large countries can have a global significance. ${ }^{3}$ For example, studies have investigated subnational regions in China, ${ }^{5,7,16,18-24}$ Brazil, ${ }^{25,26}$ Australia, ${ }^{27}$ and EU countries. ${ }^{28-30}$ These studies highlight three main issues: (1) treating a very large nation (e.g., China, which drives $\sim 30 \%$ of global material flow) as a homogeneous entity within a global multiregional input-output table (GMRIO) may mean researchers are unable to analyze important dynamics in the trade; ${ }^{5,20,31}$ (2) it may bring bias to national results in total, ${ }^{26,32-34}$ and (3) policymakers may struggle to convert messages from global and national analyses to regional strategies and targets. ${ }^{18,22,24,25,31,32}$

Early EE-IO studies often used a single-region input-output (SRIO) table. However, to be able to account for trade, researchers had to make certain assumptions, e.g., that imports

Received: July 16, 2020

Revised: August 26, 2020

Accepted: August 26, 2020

Published: August 26, 2020 
were produced with the same technology as the importing country (i.e., that an electronic product imported from Japan into the U.S.A. is assumed to have been produced with U.S. technologies rather than Japanese). This approach is called the domestic technology assumption (DTA) and can lead to large accounting errors because, as described, it does not differentiate between imported goods and that produced locally. ${ }^{8,35,36}$ Taking China's subnational study as an example, early works used Chinese interprovincial input-output tables (IOTs) alone to explore provincial footprints and virtual transfer of environmental pressures within the country. $7,19,23,37$ As the focus is interprovincial, the environmental pressures embodied in international imports were often either not included or estimated using the DTA. ${ }^{7,22}$

Advancements in multiregional input-output (MRIO) models and later in global multiregional input-output (GMRIO) models allowed researchers to trace footprints in a global context and with improved accuracy. ${ }^{11,17}$ It is considered as a more comparable and consistent framework to estimate footprints ${ }^{38}$ and is adopted by the International Resource Panel of UN Environment for material footprint (MF) assessments. ${ }^{2,3}$

Further, there have been several studies combining a local IOT with a GMRIO. They typically nest a subnational IOT $^{39-42}$ (which are generally for Chinese interprovincial $\operatorname{IOT}^{5,15,16,20,21,31,32,43}$ ) or a city-level IOT $^{44-46}$ within a GMRIO. Compared to the DTA, this represented a significant step forward, allowing researchers to distinguish the impacts of different technologies within nations while allowing for exploring linkages between the local and the global economy (especially in large countries like China). These approaches are especially important for investigating the degree of integration of Chinese provinces in global value chains. ${ }^{43,47}$

The core process of such an analysis is to connect data for each sector in each subnational area using the subnational IOT to the data for each sector in each country (or region) in a GMRIO. Neither the Chinese interprovincial IOT nor any GMRIO provides these links between provinces and foreign countries. As such, without additional data input, researchers have typically had no choice but to connect the two IOTs by assuming that the international imports/exports of an economic sector in a province are distributed among all foreign countries/regions in the same proportion as China's exports/imports for that sector (we will call this the trade structural assumption, or TSA). ${ }^{20,21,24,31}$ Although this is a reasonable, practical approach, it could also introduce errors. This simplification of trade structure means that the differences in how different provinces connect to international trade and interact with foreign countries are neglected. Previous studies have highlighted that the use of the TSA approach requires further analysis and investigation. ${ }^{16,24,41}$

Overcoming this TSA simplification presents a key data and knowledge gap. Previous economic studies showed that the trade structure among domestic regions and foreign countries are essential to subnational modeling. ${ }^{16,41,43,48}$ Other studies in economies have embedded the domestic inter-regional IOT (of China and Japan) into OECD intercountry IOT using regional trade data to measure the global value chain of Chinese domestic linkages ${ }^{43,49}$ and their associated carbon emissions. ${ }^{15}$ As yet, a comparison between these methods has not been published.

Previously, we investigated China's material footprint (MF) at the sectoral and provincial level. ${ }^{5}$ While the assessment of environmental pressures using EE-IO is always dependent on the quality of data and methodological approaches, the material footprint modeling is particularly sensitive compared to other footprints. ${ }^{50}$ This is because while emissions can occur across sectors and regions, material extraction activities are highly specialized in primary sectors in which resources are extracted and then propagate through the supply chains and finally to the consumer. ${ }^{3,50}$ This necessitates the exploration of further methods for constructing databases for such analyses, including incorporating subnational customs data in the EE-IO framework.

Here we assess material footprint (MF) using two approaches, the traditional trade structural assumption (TSA) and a customs-linked database. The same analytical, EE-IO framework is used in both cases to isolate the differences to the database construction. We explore these differences using a case study of $23 \mathrm{MF}$ types in China. We present the MF at the national level and then examine differences across three different data dimensions: by materials, by provinces, and by the international outsourcing patterns.

\section{EE-IO BASICS, TSA, AND DIRECT-LINKING}

2.1. EE-IO for Material Footprint. In calculating footprints under EE-IO, we apply the standard Leontief model: ${ }^{4,51-53}$

$$
\mathrm{MF}=K(I-A)^{-1} y
$$

where MF is the material footprint driven by the final demand $y . K$ is the intensity matrix indicating the domestic extraction (DE) per unit of each economic sector's total output in each sector in each region. $(I-A)^{-1}$ is the Leontief inverse matrix, where $I$ is the identity matrix, and $A$ is the technical coefficients matrix. In our case study, we used the Chinese provincial MRIO tables ${ }^{54}$ (to which we added additional details in resource-extraction sectors) with EXIOBASE v3.4 $4^{55}$ as the GMRIO, both for 2010. Using the highest common spatial and sectoral resolution across these tables, we obtained a table representing 30 provinces and 48 countries/regions. Each region includes data on 48 sectors. We refer to the Supporting Information (SI) and earlier work ${ }^{5}$ for the detailed procedures for harmonizing and processing the two IOTs.

In this model, we cover four main material categories (biomass, fossil fuels, metal, and nonmetallic minerals) including 29 material subtypes spread across these four categories. For ease of reporting and analysis, we group all types into 23 categories (indicated in SI Tables S6 and S7). Using standard accounting frameworks outlined by Eurostat ${ }^{56}$ and UN Environment IRP, ${ }^{57,58}$ we established a consistent material extraction database at both international and Chinese provincial levels. Classification details and data sources are presented in SI Section S2.

2.2. Linking the National MRIO (Interprovincial IOT) to a GMRIO. We now outline the two approaches for linking the Chinese interprovincial IOT (a subnational MRIO) with a GMRIO: the TSA often used in the literature and directlinking is presented here.

i. Assuming Proportionality: Trade Structural Assumption (TSA). An overview of linking using the TSA is shown in Figure 1. The MRIO (the Chinese interprovincial IOT in this case) provides the trade vectors (dark blue blocks) among provinces and the aggregated outside-of-China trade (i.e., provinces-toworld) while the GMRIO provides the import/export vectors 


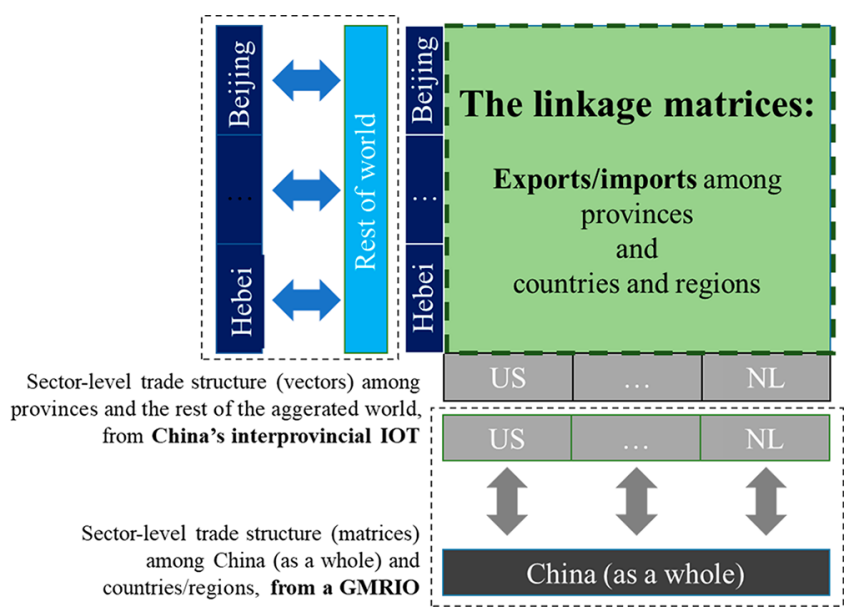

Figure 1. Schematic linkage process with the Chinese interprovincial IOT and GMRIO.

(light gray blocks) among China as a whole and other countries (i.e., China-countries/regions).

First, we take GMRIO (i.e., EXIOBASE) as a control total to scale up Chinese interprovincial IOT. Then we obtain the exports and imports (i.e., linking matrices) among provinces and countries (i.e., provinces-to-countries and vice versa) by assuming that international exports/imports in each sector for each province to other countries are in the same proportion as China's overall exports/imports. The exports/imports matrices can be disaggregated as follows:

$$
z_{i, j}^{r, s}=z_{i, j}^{r} \times \frac{z_{j}^{s}}{\sum_{s} z_{j}^{s}}
$$

where $z_{i, j}^{r, s}$ refers to the value (for either intermediate use or finial demand) in the linkage (exporting/exporting) matrices reflecting the exports (or imports; we take exports for an example here) between sector $j$ of province $s$ and sector $i$ of the country/region $r . z_{i, j}^{r}$ refers to the value in the export matrix in the GMRIO that the (relative) exporting amount of sector $i$ in country/region $r$ to the sector $j$ in China. The term $\frac{z_{j}^{s}}{\sum_{s} z_{j}^{s}}$ indicates the proportion used to disaggregate sector $j$ of province $s$ from the "China-countries/region" level to the "provinces-to-countries" level. The TSA hence does not consider that the same sector in different provinces may export to a different mix of countries. In other words, the proportion of production through different sectors $\left(\frac{z_{j}^{s}}{\sum_{s} z_{j}^{s}}\right)$ for the export structure of goods from Beijing, Shanghai, or any other provinces to the United States are assumed to the same (as China's aggregated structure). The same applies, mutatis mutandis, for imports.

ii. Trade Data Linkage (Direct-linking). For direct-linking, the actual province-specific trade structure is used to link Chinese interprovincial IOT and the GMRIO, EXIOBASE. We used the Chinese Customs Trade Statistics database (CCTS) and extracted the trade records between provinces and foreign countries/regions. We then harmonized these data to the spatial and sectoral resolution of our model (see SI Section 2.2). The CCTS database provides information for each import/export record, including the location information, HS code (Harmonized Commodity Description and Coding
Systems) of products, transaction values, physical amounts, and more. Note that there are three types of location information: (a) the registered location of importers/exporters (the company), (b) the place of actual destination/origin of goods, and (c) the customs port. The data classified by the location of importers/exporters (the company) are not suitable since many companies own branches and factories in different provinces and their trade activities may be recorded under the headquarters or a subsidiary company. It is not possible to use the customs port data either since the goods could be continuously transported domestically. However, because we have the actual place of use, we can use these data. ${ }^{59}$ This is consistent with the assumptions used for compiling the Chinese interprovincial IOT. ${ }^{54}$

In general, the procedure to link provinces to the GMRIO is similar to compiling a GMRIO by treating every province as a "virtual country". ${ }^{55,60-62}$ Inconsistent statistics are common when compiling IOT with multiple data sets under different statistical systems. Mathematical techniques are used to reconcile and harmonize the different data input. ${ }^{60,63}$ In our model, one important principle is to use existing IOTs (i.e., EXIOBASE and Chinese interprovincial IOT) as a control total since they have been previously harmonized. ${ }^{43}$ We restrict our alternations to relative differences derived from trade statistics, rather than the absolute amounts. This is because absolute amounts can vary due to differences in cost, insurance, and freight of trade goods (CIF), as well as potential discrepancies among the system of national accounts (SNA), input-output model, and CCTS data sets. We assume that any differences this may introduce would be moderated by the fact that the provincial IOT and the customs data are from the same Chinese statistical system.

Then we extract the relative structure (as a ratio, rather than the absolute value) from the CCTS data set and use it to disaggregate each value in the original matrices of China's import/export in EXIOBASE resulting in 30 data points for 30 provinces. One important assumption is how to distribute the relative structure. As trade statistics only provide HS code, location information, assumptions have to be made to obtain the input-output relations of a given product. (For example, we know the amount of cars exporting from Japan to Beijing based on customs statistics but we need to further allocate the input of Japanese cars to Beijing's every sector). We assume that each given sector of every province uses the imported goods from the sector of a country (imported cars from Japan to Beijing) proportionally to the use structure of domestic inputs (how Japanese cars are used in Beijing's different sectors is in the same way as domestically made cars are used in Beijing's various sectors). It considers a more comprehensive situation avoiding errors in extreme cases-a province is dominated in an industry nationally or does not have the industry at all (see SI Section 1.1 for comparisons on other options). Equation 3 describes the option (d):

$$
z_{i, j}^{r, s}=z_{i, j}^{r} \times \frac{t s_{i}^{r, s}}{\sum_{s} t s_{i}^{r, s}} \times \frac{\sum_{s} i o_{-} t_{i, j}^{r, s}}{\sum_{j} \sum_{s} i o_{-} t_{i, j}^{r, s}}
$$

where the term $\left(z_{i, j}^{r, s}\right)$ gives the imports between sector $j$ of province $s$ and sector $i$ of the country/region $r$ (for intermediate use and finial demand) and can be obtained as splitting the national value $z_{i, j}^{r}$ by multiplying the trade structure ratio $\left(\frac{t t_{i}^{r, s}}{\sum_{s} t s_{i}^{r, s}}\right)$, where $t s_{i}^{r, s}$ indicates the actual trade 
volume between of province $s$ and country/region $r$. The term $i o_{-} t_{i, j}^{r, s}$ refers to the value in the intermediate use/final demand matrices of IOTs and $\left(\frac{\sum_{s} i_{-} t_{i, j}^{r, s}}{\sum_{j} \sum_{s} i_{-} t_{i, j}^{r, s}}\right)$ described the use structure of domestic inputs.

A further problem is that CCTS data cover products and not trade in services. We make another assumption that regions that import more goods would also purchase more services of the same trading partners. ${ }^{43}$ Therefore, we use the structure of goods trade as a proxy of services trade. We investigate the sensitivity of the results to this assumption by setting the trade in services to 0 . We find that services have a very small impact on MF-the average change of provincial MF is $-0.16 \%$ (see SI Section 1.3 for details). After this, an afterward balancing technique $^{43,64}$ shall be applied.

\section{RESULTS}

In this section, first, we will present the aggregated impacts of different approaches at the national level. National-level indicators are calculated based on three approaches: the direct-linking (to nest the interprovincial IOT in EXIOBASE by regional trade data), the TSA (to nest the interprovincial IOT in EXIOBASE by proportionality assumption), and using EXIOBASE (the national-specific GMRIO) directly. Then we focus on the differences in the results using the TSA and direct-linking approaches across three different data dimensions: materials, provinces, and patterns of international outsourcing.

3.1. Aggregated Impacts at the National Level. Material footprint and material embodied in the trade of China (or the national sum for subnational model) are calculated by EXIOBASE alone and the two above-described nested models (based on the direct-linking and TSA), respectively. Results show nesting a regional-specific IOT into a GMRIO will not introduce large discrepancies on the national material footprint of China and other countries/ regions. Even though the direct-linking and TSA introduce subnational heterogeneities, Chinese national MF by the direct-linking and TSA is only changed $\sim 4 \%$ comparing to the country-specific model (Figure 2). For MF of other countries/ regions, the discrepancies in most cases are within $\pm 1 \%$ (see Tables S2-S4 in the SI). This confirms that the influence of spatial resolution on calculating the overall footprint is limited. $^{50}$

However, we see large discrepancies in internal flows (e.g., materials embodied in exports and imports). It is because structures and resolution of Chinese parts in IOT have been improved. Both TSA and direct-linking approaches decrease Chinese national MF embodied in exports by $13.7 \%$ and $22.8 \%$ compared to using EXIOBASE directly (see aggregated MF results in Figure 2 and results of disaggregated materials in Figure S3 in the SI). It is similar to previous studies in carbon and water since the subnational-spatial and trade heterogeneity are introduced. ${ }^{26,32-34,65}$ However, it is different for imports. TSA only brings minor ( $0.2 \%)$ differences compared to using EXIOBASE alone, while the direct-linking approach decreases national material embodied in imports by $18 \%$. TSA does not lead to large changes because the extractive intensities (matrices) of foreign countries/regions remain unchanged in the model. And their exporting structures to China (compared with the direct EXIOBASE approach) are proportionally disaggregated to provinces by TSA, which are equivalent to the

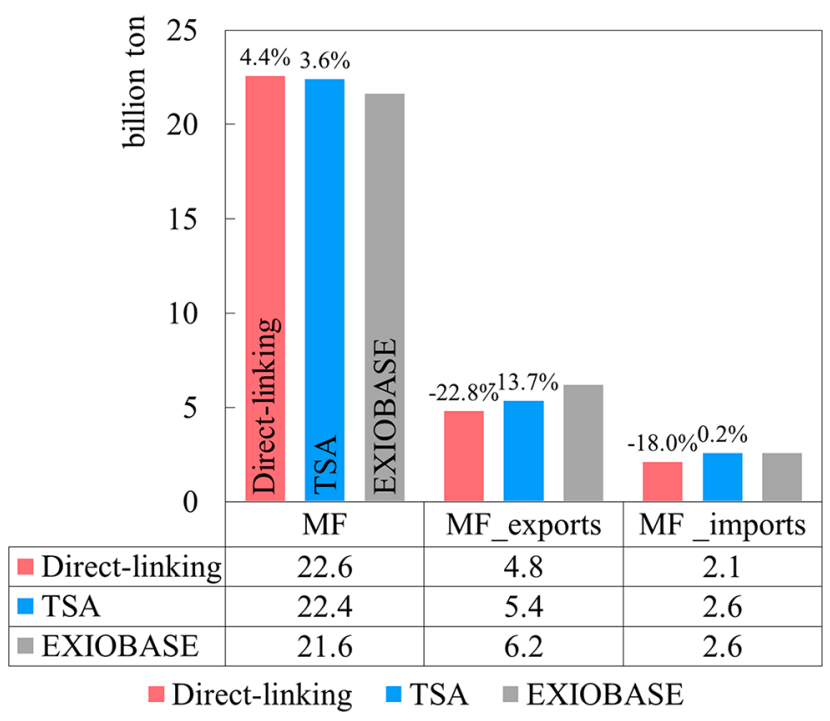

Figure 2. Comparison results, material footprint (MF), MF embodied in exports, and MF embodied in imports of China. The results are calculated by the direct-linking approach in red, the TSA approach in blue, and EXIOBASE directly in gray.

aggregated counterparts in the EXIOBASE. While for the direct-linking, the trade customs reshape the importingstructure of each trading pair between provinces and countries/regions so it presents differences.

3.2. By Material. Then we move to the province-specific analysis on the differences for TSA and direct-linking approaches. A positive difference means that direct-linking increases the size of the result compared to TSA and a negative result represents the opposite. The results of aggregated MF vary from $-9.2 \%$ to $+14.2 \%$ across the 30 provinces (see Figure S4 and Table S5 in the SI for a detailed statistical description). As the material footprint is an aggregated indicator (i.e., for all material extraction combined), we further investigated such variations for 23 (grouped) categories of materials one-by-one. Figure $3 \mathrm{~A}$ shows the proportion of MF sourced internationally by China using EXIOBASE alone (without linking China's interprovincial IOT). The top five important materials embodied in trade in terms of percentage were oil-bearing crops $(82 \%)$, chemical/fertilizer materials (80\%), forestry products $(77 \%)$, natural gas $(75 \%)$, and oil (71\%). While the bottom five were sand/clay (1\%), nuts/ vegetables/fruits $(4 \%)$, stone $(5 \%)$, cereal $(11 \%)$, and coal (14\%). Figure 3B shows the percentage change in the estimated footprint for 23 resource categories between direct-linking and TSA across 30 provinces. Unsurprisingly, the TSA approach results in large differences with directlinking for resource categories with a large proportion of imports. Across provinces, the largest deviation was found in oil-bearing crops (ranging from $-67 \%$ to $179 \%$ ), chemical/ fertilizer materials (ranging from $-60 \%$ to $143 \%$ ), forestry products (ranging from $-56 \%$ to $127 \%$ ), natural gas (ranging from $-69 \%$ to $109 \%$ ), and oil (ranging from $-53 \%$ to $104 \%$ ). The difference among provinces of a given resource is much smaller for materials that are traded less in international markets (e.g., sand/clay), with a general range of $-5 \%$ to $10 \%$. Further, we explored the correlation between the two data sets (percentage of China's MF sourced from imports vs percentage change in MF). The coefficient of determination, $R^{2}$ reached 0.92 (see Figure 3C), which supports our inference 


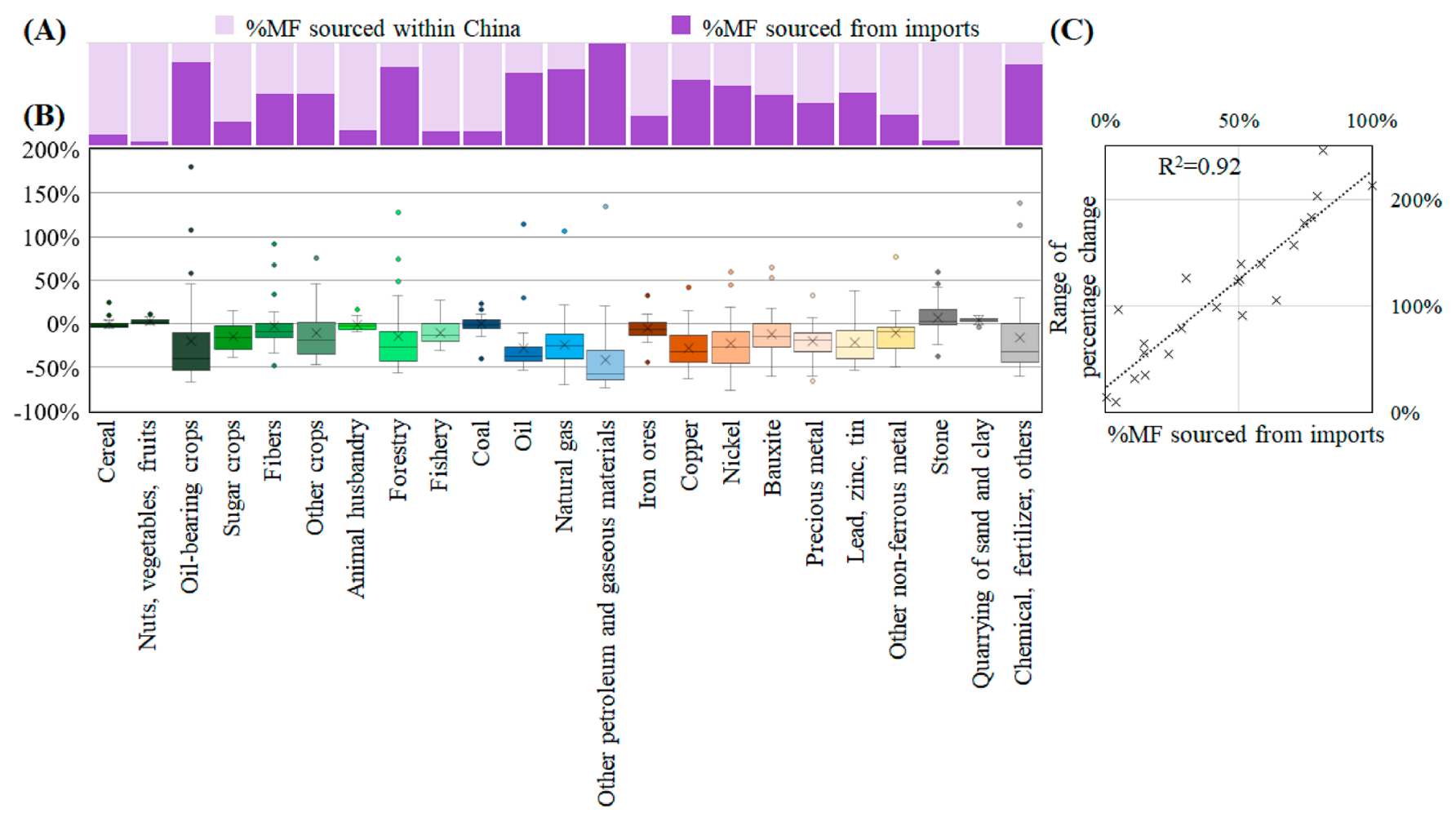

Figure 3. (A) Percentage of China's MF sourced from imports of 23 types of resources. (B) Box-and-whisker plots of the differences between the provincial MF of 23 types of resources calculated by the TSA and direct-linking approaches. The horizontal line is the median, the cross is the mean, the interquartile range (IQR) is equal to the difference between the $75^{\text {th }}$ and $25^{\text {th }}$ percentiles, the maximum length of whiskers is 1.5 times the interquartile range, and single points are outliers. (C) Percentage of China's MF sourced from imports vs the range of variation calculated based on the TSA and direct-linking. Note the percentage of imports of "other petroleum/gaseous materials" in panel A is $100 \%$ since this category is not individually accounted in 2010 in Chinese statistical systems.

that as the percentage of imported MF increases as a proportion of total domestic demand, the differences between the TSA and direct approaches also increase. Generally, metal, fossil fuels, and biomass, whose cross-border transportation is more frequent, see a larger difference than nonmetallic minerals (which generally rely on local extraction).

3.3. By Province. We present the difference in the province-level material footprint by material category between the TSA approach and direct linking in Figure 4. As expected, coastal provinces show relatively larger errors because they are more integrated into the global supply chain. For instance, the direct-linking results show that Guangdong has a $14 \%$ higher aggregated MF, 32\% higher biomass footprint, and 34\% metal footprint than when using the TSA approach. The size of MF underestimation for Guangdong is $188 \mathrm{Mt}$, which is almost equivalent to the total MF of Hainan (an island province in southern China) with an MF of $186 \mathrm{Mt}$ and a population of 8.7 million in 2010. Similar results were seen in Fujian (21\% higher in metals), Shanghai (16\% higher in biomass), and Jiangsu ( $15 \%$ higher in fossil fuels), among others. Besides we find an outlier-Hainan, an island province in southern China, who sees $-48 \%$ of deviations in fossil fuels. It is because its energy demands in 2010 were met by crude oil and natural gas (the largest proportion across provinces) - the vast majority of which were imported. ${ }^{66}$

In contrast, the MF of most inland provinces appears, in general, overestimated using the TSA approach but the magnitude of underestimation is lower than for coastal provinces. In most cases, differences among inland areas are within $\pm 10 \%$ with slightly larger differences in metals.
Generally, this is consistent with the argument we made above that the aggregated metals have a larger proportion (36\%) of imported MF than fossil fuels (24\%), biomass (19\%), and nonmetallic minerals (4\%).

3.4. By Outsourcing Structure. We further investigated the differences in the imported MF embodied in trade across provinces. As shown in Figure 5, the largest differences were generally found in the material transfer embodied in imports rather than exports. This may be because imported MF largely rely on foreign production technologies of materials, which are then distributed through the importing matrix. The uncertainty of the TSA method has a great impact here. Figure 5 further shows that the percentage changes of imported MF across provinces range from $-80 \%$ to $141 \%,-73 \%$ to $63 \%,-76 \%$ to $87 \%$, and $-73 \%$ to $153 \%$ for biomass, fossil fuels, metals, and nonmetallic minerals, respectively.

These variations also reflect the extent to which the economies of different provinces rely on resource extractive activities and production with important international imports/exports. Resource-poor coastal provinces with large volumes of imported materials (larger bubble size in Figure 5) see the largest deviations between the TSA and direct-linking approaches. Most are clustered in the upper-right quadrant in Figure 5 where both imported and exported MF are underestimated (while imported MF are underestimated at a larger magnitude). In contrast, material extraction in China is highly concentrated inland (central and western areas), but the inland provinces trade much less with foreign countries. ${ }^{5,23}$ As they have a smaller size of MF exports and imports, the uncertainties are also smaller than those of coastal provinces. 


\begin{tabular}{|c|c|c|c|c|c|}
\hline Liaoning NE & $2 \%$ & $2 \%$ & $-2 \%$ & $5 \%$ & \multirow{2}{*}{$\begin{array}{l}2 \% \\
2 \% \\
\end{array}$} \\
\hline Jilin NE & $-1 \%$ & $-6 \%$ & $-5 \%$ & $-6 \%$ & \\
\hline Heilongjiang NE & $5 \%$ & $-3 \%$ & $-4 \%$ & $-5 \%$ & $12 \%$ \\
\hline Beijing NC & $-2 \%$ & $-6 \%$ & $0 \%$ & $-9 \%$ & $-0 \%$ \\
\hline Tianjin NC & $-3 \%$ & $-3 \%$ & $-8 \%$ & $-15 \%$ & $0 \%$ \\
\hline Hebei NC & $-1 \%$ & $-7 \%$ & $-4 \%$ & $-7 \%$ & $2 \%$ \\
\hline Shandong NC & $1 \%$ & $2 \%$ & $6 \%$ & $-17 \%$ & $2 \%$ \\
\hline Shanghai EC & $-2 \%$ & $16 \%$ & $0 \%$ & $-6 \%$ & $-7 \%$ \\
\hline Jiangsu EC & $3 \%$ & $3 \%$ & $15 \%$ & $5 \%$ & $1 \%$ \\
\hline Zhejiang EC & $-9 \%$ & $7 \%$ & $5 \%$ & $9 \%$ & $-16 \%$ \\
\hline Fujian SC & $10 \%$ & $8 \%$ & $6 \%$ & $21 \%$ & $10 \%$ \\
\hline Guangdong SC & $14 \%$ & $32 \%$ & $13 \%$ & $34 \%$ & $8 \%$ \\
\hline Hainan SC & $-2 \%$ & $-0 \%$ & $-48 \%$ & $-17 \%$ & $1 \%$ \\
\hline Shanxi YL & $0 \%$ & $-5 \%$ & $-6 \%$ & $-12 \%$ & $6 \%$ \\
\hline InnerMongolia YL & $-2 \%$ & $-7 \%$ & $-5 \%$ & $-15 \%$ & $2 \%$ \\
\hline Henan YL & $-3 \%$ & $-7 \%$ & $-9 \%$ & $-19 \%$ & $3 \%$ \\
\hline Shaanxi YL & $-1 \%$ & $-2 \%$ & $-2 \%$ & $-12 \%$ & $2 \%$ \\
\hline Anhui YT & $-3 \%$ & $-10 \%$ & $-7 \%$ & $-14 \%$ & $1 \%$ \\
\hline Jiangxi YT & $-5 \%$ & $-10 \%$ & $-22 \%$ & $-29 \%$ & $6 \%$ \\
\hline Hubei YT & $2 \%$ & $-9 \%$ & $-7 \%$ & $-15 \%$ & $6 \%$ \\
\hline Hunan YT & $-2 \%$ & $-10 \%$ & $-11 \%$ & $-14 \%$ & $3 \%$ \\
\hline Guangxi SW & $3 \%$ & $-2 \%$ & $-7 \%$ & $-17 \%$ & $6 \%$ \\
\hline Chongqing SW & $-0 \%$ & $-9 \%$ & $-8 \%$ & $-22 \%$ & $3 \%$ \\
\hline Sichuan SW & $1 \%$ & $-11 \%$ & $-7 \%$ & $-7 \%$ & $5 \%$ \\
\hline Guizhou SW & $4 \%$ & $-4 \%$ & $-8 \%$ & $-11 \%$ & $9 \%$ \\
\hline Yunnan SW & $4 \%$ & $-4 \%$ & $-4 \%$ & $-10 \%$ & $9 \%$ \\
\hline Gansu NW & $-1 \%$ & $-4 \%$ & $-2 \%$ & $-15 \%$ & $1 \%$ \\
\hline Qinghai NW & $2 \%$ & $-2 \%$ & $-4 \%$ & $-19 \%$ & $6 \%$ \\
\hline Ningxia NW & $-3 \%$ & $-9 \%$ & $-3 \%$ & $-20 \%$ & $-1 \%$ \\
\hline Xinjiang NW & $4 \%$ & $4 \%$ & $-4 \%$ & $-5 \%$ & $7 \%$ \\
\hline
\end{tabular}

Figure 4. Difference in province-level material footprints by material category between the direct linking and the TSA approach. Percentage changes indicate the reduction/increase of the direct-linking compared to the TSA approach. The capitalized abbreviations give the region to which a province belongs: NE, northeast; NC, north coast; YL, Yellow River midstream; YT, Yangtze River midstream; EC, east coast; SC, south coast; SW, southwest; and NW, northwest.

Most inland provinces are clustered in the bottom-left quadrant of Figure 5, where both imported and exported MF are overestimated. The differences between the two approaches can partially offset one another for the final MF under some conditions. For example, the MF imports and exports of Hunan were overestimated by $45.3 \mathrm{Mt}$ and $49.0 \mathrm{Mt}$, respectively. Thus, difference for Hunan's international PTB deviates by just $3.7 \mathrm{Mt}$, accounting for $0.5 \%$ of total MF. This also suggests why the TSA approach deviates less for inland provinces, provided that the MF estimation is done at the aggregated (net of imports) level.

In addition, we investigated the influence of the TSA approach on the interprovincial (embodied) material flows (see Figure S5 in the SI). The overall domestic flows are similar (with only a $3 \%$ difference). However, because directlinking decreases the size of imported MF for some provinces (for example, for the inland provinces discussed above), it will generally increase the domestic flows toward those provinces. As a result, direct-linking shows a higher reliance on domestic extraction than the TSA. For coastal provinces, the trend is the opposite. EE-IO reallocates the production-based flows (DE) to the consumption-based flows (MF) of a region/sector. Even though the two interprovincial input-output matrices in the two approaches are the same, direct-linking, with its different importing/exporting matrices, causes ripple effects through the model and alters interprovincial flows, resulting in a better reflection of real material flows.
Moreover, perhaps the biggest issue in using the TSA approach is that it cannot distinguish the differences between trading partners, i.e., it assumes that each province follows the same trading structure as at the national level. Figure 6 shows the origin of international imported MF embodied in outsourced production for different regions for each province, explicitly showing the difference between the TSA and directlinking approaches. The direct-linking approach shows regional disparities (Figure 6A) compared to the more homogeneous composition across provinces shown by the TSA approach (Figure 6B). For example, consider a dominant country pair of China and the U.S. (where the U.S. is the largest of China's trade partners and comprises $\sim 11 \%$ of imported Chinese MF). Approximately, $10 \%-12 \%$ of provincial MF are comprised of raw material extracted in the US and imported to China. However, if we consider the actual trade structure, then the direct results show that the proportion varies much more, from $7 \%$ to $28 \%$ across different provinces. Similar phenomena also exist in exported MF as presented in the SI Figure S6. The reduction in homogeneity shown in Figure 6 is crucial for a better understanding of trade impacts in studies that aim to link global consumption with local impacts. More detailed differences at the bilateral level (between provinces and countries/regions pairs) are presented in Figures S7 and S8 in the SI. Coastal provinces (Shanghai, Jiangsu, Guangdong, and Hainan) are under large influences. 


\section{(A) Biomass}

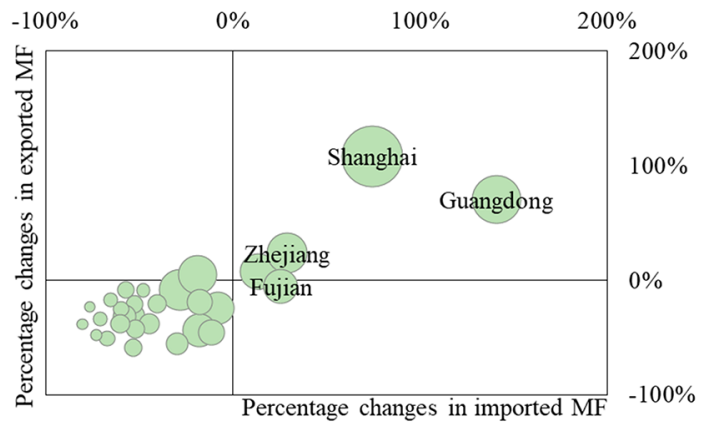

(C) Metal

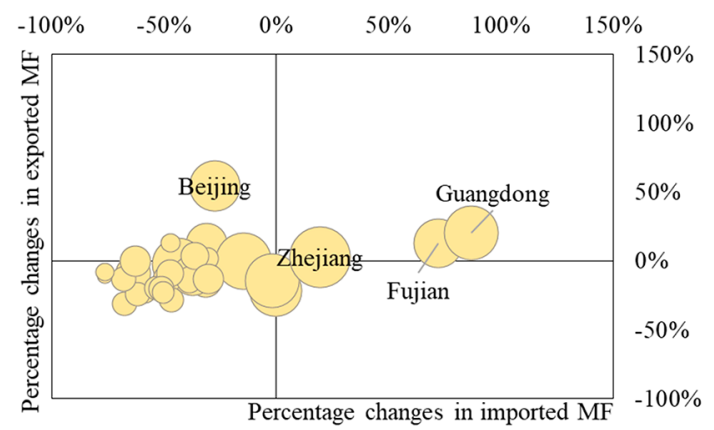

(B) Fossil Fuels

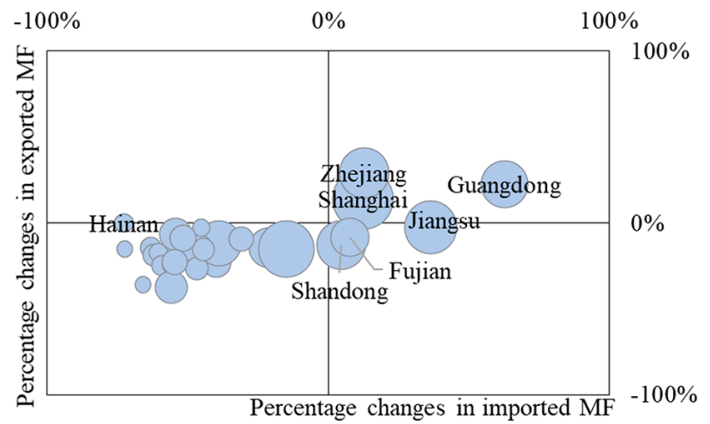

(D) Nonmetal

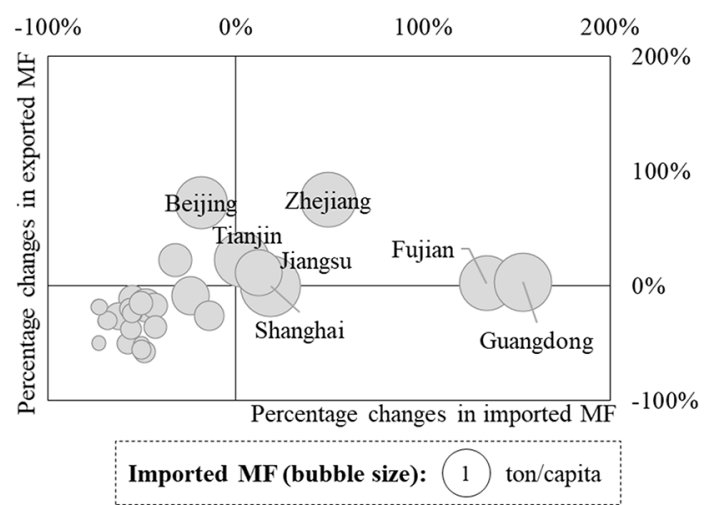

Figure 5. Bubble plot of percentage changes of material transfer embodied in international imports vs percentage changes of material transfer embodied in the international exports. The size of a bubble represents the per capita material transfer embodied in the international imports of the given province.

\section{DISCUSSION}

Subnational footprinting models are able to explore the internal supply chains of nations and connect local dynamics to the global economy. However, the approach for disaggregating national-level and sector-level data to a higher resolution both spatially and by sector, is very data-sensitive. We show that for countries that drive large material flows, such as China, estimating subnational material flows embodied in trade using proportionality in disaggregating data may lead to large differences when compared with using proxy data such as customs records.

At the aggregated national level, even though considering subnational spatial heterogonies for China by TSA, which have adjusted the amount of overestimation in material embodied in exports to some extent, the material embodied in both exports and imports are still overestimated. The direct-linking approach further decreases the material embodied in exports and imports by $9.1 \%$ and $18.2 \%$ compared to TSA. These confirm that it is necessary to introduce subnational heterogeneities to assess embodied flows of environmental impacts (materials, carbon, water, etc.) for big countries with vast territory and regional disparities. ${ }^{15,32,34}$ At the same time, the overall material footprints of the nations are not influenced significantly by different methods. We argue that, for footprint assessment, a country-specific GMRIO model may be sufficient enough. ${ }^{50}$ While exploring subnational supply chains should be conducted by embedding a subnational IOT within a GMRIO using trade data, especially for large countries.

At the subnational-level, the gaps in MF between the two approaches across provinces range from $-9 \%$ to $14 \%$ but are huge for disaggregated materials like metal and fossil fuels.
Differences are smaller in a relative sense across inland areas, but the MF of coastal provinces can be underestimated because these provinces have a much higher level of integration into the global economy. The largest differences are found in the material transfer embodied in imports rather than exports. With the better reflection of imports and exports at provincial and international levels, ripple effects throughout interprovincial material trade were also observed. TSA linking may partially neglect regional disparities concerning international trade between different subnational areas because it assumes that the sector distribution (structure) among trade partners of a given area is the same as at the national level, as shown in Figure 6. Therefore, the TSA approach may not be fully capable of analyzing international trade patterns and in some cases may be inappropriate for analyzing the connection between global supply chains and for example, Chinese provinces.

Our work can be seen as a step in the evolution of the use of EE-IO to calculate environmental footprints at the subnational level. Initially, only national EE-IO tables were available, and the footprints of imports were calculated using the domestic technology assumption (DTA), along with other approaches. ${ }^{35}$ For calculating subnational footprints province-level IOTs were used, also in combination with the DTA, with the rationale that such work would focus mainly on intracountry flows. ${ }^{7,19,23,37}$ For both applications, the DTA worked as a first approximation but also led to errors because it does not distinguish between environmental pressures and foreign and domestic production recipes. The development of GMRIOs overcame this limitation and also allowed for the embedding of province-level IOTs in GMRIOs. ${ }^{1,17,38,53}$ However, TSA linking was necessary to distribute imports to, and exports 


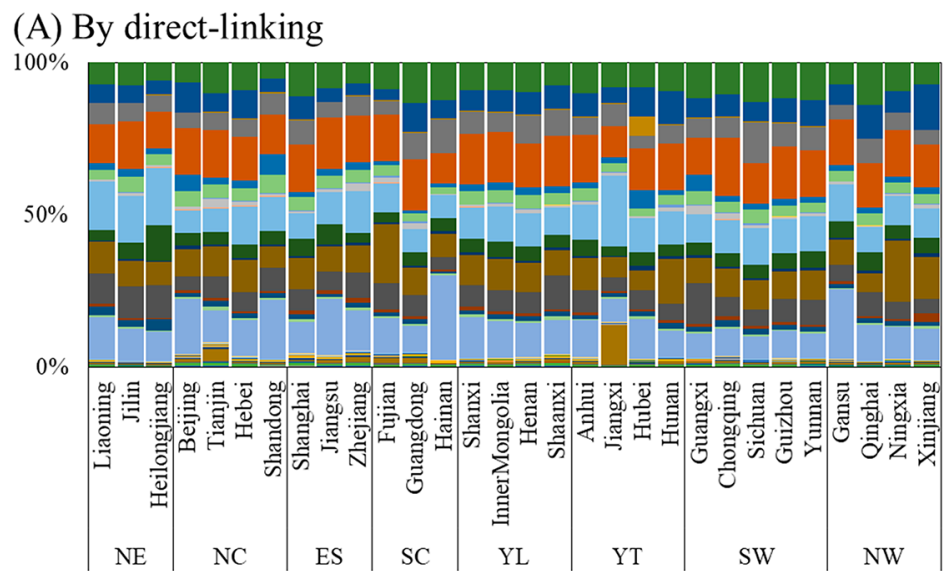

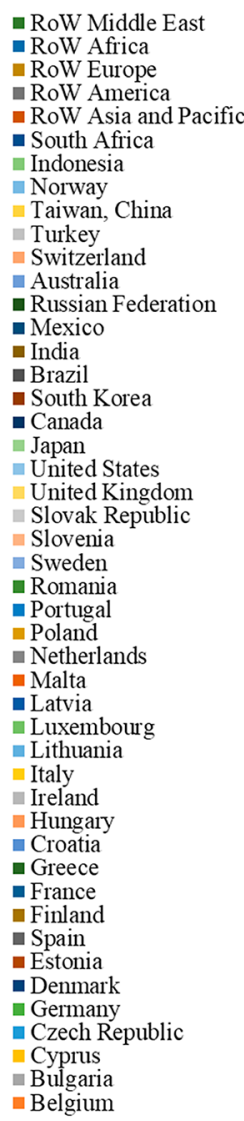

(B) By the TSA

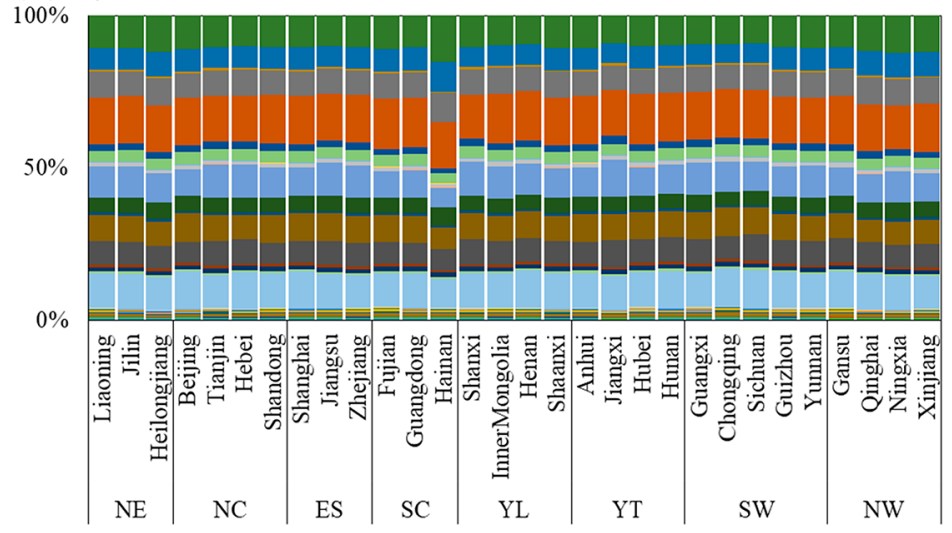

Figure 6. Outsourced origin of the MF for different regions in percentages for each province. Results derived from direct-linking and the TSA are presented in (A) and (B) respectively. The capitalized abbreviations give the region to which the province belongs: NE, northeast; NC, north coast; YL, Yellow River midstream; YT, Yangtze River midstream; EC, east coast; SC, south coast; SW, southwest; and NW, northwest.

from, a country across its regions (due to a lack of more specific information). We showed for the case of Chinese provincial MF that the use of real province-level trade data using direct-linking gives more precise results. The relevance of using direct-linking for $\mathrm{MF}$ is understandable, given the important role of China in driving the global MF, the quite different production structures and interactions with global markets of Chinese provinces, and the general finding that MF are sensitive to, for example, sector detail. ${ }^{32}$

The direct-linking approach is however extremely dataintensive because the trade data required at the provincial level can be as large as 15 million data points per year in our case. However, further applied and theoretical work could investigate to what extent the size of data sets would impact results. It may be the case that fewer data points are needed. Additionally, similar analyses could be applied to other countries that have the requisite subnational statistics and subnational IOTs. A further important follow-up question is also whether these differences are also relevant for other footprints such as carbon emissions and water, or whether other footprints still give a good approximation using the TSA approach. Furthermore, recent works also showed distinguishing ordinary and processing exports would also lead to differences in carbon exports. ${ }^{32,67}$ How this effect would influence material flows could be further explored.

\section{ASSOCIATED CONTENT}

\section{SI Supporting Information}

The Supporting Information is available free of charge at https://pubs.acs.org/doi/10.1021/acs.est.0c04728.

Supplementary results and a more detailed discussion of methodologies and data availability (PDF)

\section{AUTHOR INFORMATION}

\section{Corresponding Authors}

Bing Zhu - Department of Chemical Engineering and Institute for Circular Economy, Tsinghua University, Beijing 100084, P. R. China; Energy Program, International Institute for Applied Systems Analysis, Laxenburg A-2361, Austria; 이이.org/ 0000-0002-2890-7523; Email: bingzhu@

mail.tsinghua.edu.cn

Arnold Tukker - Institute of Environmental Sciences (CML), Leiden University, 2333 CC Leiden, The Netherlands; The Netherlands Organisation for Applied Scientific Research TNO, 2595 DA Den Haag, The Netherlands; Email: tukker@ cml.leidenuniv.nl

\section{Authors}

Meng Jiang - Department of Chemical Engineering, Tsinghua University, Beijing 100084, P. R. China

Lin Liu - Department of Chemical Engineering, Tsinghua University, Beijing 100084, P. R. China

Paul Behrens - Institute of Environmental Sciences (CML), Leiden University, 2333 CC Leiden, The Netherlands; Leiden 
University College The Hague, 2595 DG The Hague, The Netherlands; (1) orcid.org/0000-0002-2935-4799

Tao Wang - Department of Chemical Engineering, Tsinghua University, Beijing 100084, P. R. China

Zhipeng Tang - Key Laboratory of Regional Sustainable Development Modeling, Institute of Geographic Sciences and Natural Resources Research, Chinese Academy of Sciences, Beijing 100101, P. R. China

Dingjiang Chen - Department of Chemical Engineering and Institute for Circular Economy, Tsinghua University, Beijing 100084, P. R. China

Yadong Yu - School of Business, East China University of Science and Technology, Shanghai 200237, P. R. China

Zijian Ren - Department of Chemical Engineering, Tsinghua University, Beijing 100084, P. R. China

Shengjun Zhu - College of Urban and Environmental Sciences, Peking University, Beijing 100871, P. R. China

Complete contact information is available at:

https://pubs.acs.org/10.1021/acs.est.0c04728

\section{Author Contributions}

${ }^{\text {II }}$ These authors contributed equally to this work.

\section{Notes}

The authors declare no competing financial interest.

\section{ACKNOWLEDGMENTS}

The authors would like to acknowledge the support of the National Natural Science Foundation of China Grants (41661144023 and 71690244). EXIOBASE v3 used in this paper was developed with funding of the European Commission, Seventh Framework Programme (FP7), grant number 308552, Development of a System of Indicators for a Resource Efficient Europe (DESIRE) project.

\section{REFERENCES}

(1) Wiedmann, T.; Lenzen, M. Environmental and social footprints of international trade. Nat. Geosci. 2018, 11 (5), 314-321.

(2) International Resource Panel Global Material Flows and Resource Productivity. An Assessment Study of the UNEP International Resource Panel; United Nations Environment Programme: Paris, 2016.

(3) International Resource Panel Global Resource Outlook 2019: Natural Resources for the Future We Want; United Nations Environment Programme: Nairobi, 2019.

(4) Wiedmann, T. O.; Schandl, H.; Lenzen, M.; Moran, D.; Suh, S.; West, J.; Kanemoto, K. The material footprint of nations. Proc. Natl. Acad. Sci. U. S. A. 2015, 112 (20), 6271-6276.

(5) Jiang, M.; Behrens, P.; Wang, T.; Tang, Z.; Yu, Y.; Chen, D.; Liu, L.; Ren, Z.; Zhou, W.; Zhu, S.; He, C.; Tukker, A.; Zhu, B. Provincial and sector-level material footprints in China. Proc. Natl. Acad. Sci. U. S. A. 2019, 116 (52), 26484-26490.

(6) Plank, B.; Eisenmenger, N.; Schaffartzik, A.; Wiedenhofer, D. International Trade Drives Global Resource Use: A Structural Decomposition Analysis of Raw Material Consumption from 19902010. Environ. Sci. Technol. 2018, 52 (7), 4190-4198.

(7) Qian, Y.; Behrens, P.; Tukker, A.; Rodrigues, J. F.; Li, P.; Scherer, L. Environmental responsibility for sulfur dioxide emissions and associated biodiversity loss across Chinese provinces. Environ. Pollut. 2019, 245, 898-908.

(8) Peters, G. P. From production-based to consumption-based national emission inventories. Ecol. Econ. 2008, 65 (1), 13-23.

(9) Davis, S. J.; Caldeira, K. Consumption-based accounting of $\mathrm{CO} 2$ emissions. Proc. Natl. Acad. Sci. U. S. A. 2010, 107 (12), 5687-5692.

(10) Eisenmenger, N.; Wiedenhofer, D.; Schaffartzik, A.; Giljum, S.; Bruckner, M.; Schandl, H.; Wiedmann, T. O.; Lenzen, M.; Tukker, A.; Koning, A. Consumption-based material flow indicators -
Comparing six ways of calculating the Austrian raw material consumption providing six results. Ecol. Econ. 2016, 128, 177-186.

(11) Tukker, A.; Bulavskaya, T.; Giljum, S.; de Koning, A.; Lutter, S.; Simas, M.; Stadler, K.; Wood, R. Environmental and resource footprints in a global context: Europe's structural deficit in resource endowments. Glob. Environ. Change-Human Policy Dimens. 2016, 40, $171-181$.

(12) Weinzettel, J.; Hertwich, E. G.; Peters, G. P.; Steen-Olsen, K.; Galli, A. Affluence drives the global displacement of land use. Glob. Environ. Change-Human Policy Dimens. 2013, 23 (2), 433-438.

(13) Hertwich, E. G.; Peters, G. P. Carbon Footprint of Nations: A Global, Trade-Linked Analysis. Environ. Sci. Technol. 2009, 43 (16), 6414-6420.

(14) Steen-Olsen, K.; Weinzettel, J.; Cranston, G.; Ercin, A. E.; Hertwich, E. G. Carbon, land, and water footprint accounts for the European Union: consumption, production, and displacements through international trade. Environ. Sci. Technol. 2012, 46 (20), 10883-10891.

(15) Pei, J.; Meng, B.; Wang, F.; Xue, J.; Zhao, Z. Production sharing, demand spillovers and $\mathrm{CO} 2$ emissions: the case of Chinese regions in global value chains. Singapore Economic Review 2018, 63 (02), 275-293.

(16) Yang, Y.; Qu, S.; Cai, B.; Liang, S.; Wang, Z.; Wang, J.; Xu, M. Mapping global carbon footprint in China. Nat. Commun. 2020, 11 (1), 2237.

(17) Malik, A.; McBain, D.; Wiedmann, T. O.; Lenzen, M.; Murray, J. Advancements in Input-Output Models and Indicators for Consumption-Based Accounting. J. Ind. Ecol. 2019, 23 (2), 300-312.

(18) Dalin, C.; Hanasaki, N.; Qiu, H.; Mauzerall, D. L.; RodriguezIturbe, I. Water resources transfers through Chinese interprovincial and foreign food trade. Proc. Natl. Acad. Sci. U. S. A. 2014, 111 (29), 9774-9779.

(19) Zhao, X.; Liu, J.; Liu, Q.; Tillotson, M. R.; Guan, D.; Hubacek, $\mathrm{K}$. Physical and virtual water transfers for regional water stress alleviation in China. Proc. Natl. Acad. Sci. U. S. A. 2015, 112 (4), 1031-1035.

(20) Feng, K.; Davis, S. J.; Sun, L.; Li, X.; Guan, D.; Liu, W.; Liu, Z.; Hubacek, K. Outsourcing CO2 within China. Proc. Natl. Acad. Sci. U. S. A. 2013, 110 (28), 11654-11659.

(21) Mi, Z.; Meng, J.; Guan, D.; Shan, Y.; Song, M.; Wei, Y.-M.; Liu, Z.; Hubacek, K. Chinese CO2 emission flows have reversed since the global financial crisis. Nat. Commun. 2017, 8 (1), 1712.

(22) Zhao, H.; Zhang, Q.; Guan, D.; Davis, S.; Liu, Z.; Huo, H.; Lin, J.; Liu, W.; He, K. Assessment of China's virtual air pollution transport embodied in trade by using a consumption-based emission inventory. Atmos. Chem. Phys. 2015, 15 (10), 5443-5456.

(23) Wang, H.; Wang, G.; Qi, J.; Schandl, H.; Li, Y.; Feng, C.; Yang, X.; Wang, Y.; Wang, X.; Liang, S. Scarcity-weighted fossil fuel footprint of China at the provincial level. Appl. Energy 2020, 258, 114081.

(24) Zhang, H.; He, K.; Wang, X.; Hertwich, E. G. Tracing the Uncertain Chinese Mercury Footprint within the Global Supply Chain Using a Stochastic, Nested Input-Output Model. Environ. Sci. Technol. 2019, 53 (12), 6814-6823.

(25) Croft, S. A.; West, C. D.; Green, J. M. H. Capturing the heterogeneity of sub-national production in global trade flows. $J$. Cleaner Prod. 2018, 203, 1106-1118.

(26) Flach, R.; Ran, Y.; Godar, J.; Karlberg, L.; Suavet, C. Towards more spatially explicit assessments of virtual water flows: linking local water use and scarcity to global demand of Brazilian farming commodities. Environ. Res. Lett. 2016, 11 (7), 075003.

(27) Lenzen, M.; Geschke, A.; Wiedmann, T.; Lane, J.; Anderson, N.; Baynes, T.; Boland, J.; Daniels, P.; Dey, C.; Fry, J.; Hadjikakou, M.; Kenway, S.; Malik, A.; Moran, D.; Murray, J.; Nettleton, S.; Poruschi, L.; Reynolds, C.; Rowley, H.; Ugon, J.; Webb, D.; West, J. Compiling and using input-output frameworks through collaborative virtual laboratories. Sci. Total Environ. 2014, 485-486, 241-251.

(28) Escobedo, F.; Oosterhaven, J., Hybrid Interregional InputOutput Construction Methods: Applied to the Seven Region Spanish 
Input-Output Table. In $51^{\text {st }}$ Congress of the European Regional Science Association: "New Challenges for European Regions and Urban Areas in a Globalised World; European Regional Science Association (ERSA): Barcelona, Spain, 2009.

(29) Kronenberg, T.; Többen, J. Regional Input-Output Modelling in Germany: The Case of North Rhine-Westphalia; Forschungszentrum Jülich: Jülich, Germany, 2011.

(30) Ivanova, D.; Vita, G.; Steen-Olsen, K.; Stadler, K.; Melo, P. C.; Wood, R.; Hertwich, E. G. Mapping the carbon footprint of EU regions. Environ. Res. Lett. 2017, 12 (5), 054013.

(31) Liu, Z.; Davis, S. J.; Feng, K.; Hubacek, K.; Liang, S.; Anadon, L. D.; Chen, B.; Liu, J.; Yan, J.; Guan, D. Targeted opportunities to address the climate-trade dilemma in China. Nat. Clim. Change 2016, 6 (2), 201.

(32) Zhang, Z.; Meng, J.; Zheng, H.; Zhu, K.; Du, H.; Guan, D. Production Globalization Makes China's Exports Cleaner. One Earth 2020, 2 (5), 468-478.

(33) Su, B.; Ang, B. W. Input-output analysis of $\mathrm{CO} 2$ emissions embodied in trade: a multi-region model for China. Appl. Energy 2014, 114, 377-384.

(34) Su, B.; Ang, B. W. Input-output analysis of $\mathrm{CO} 2$ emissions embodied in trade: The effects of spatial aggregation. Ecol. Econ. 2010, 70 (1), 10-18.

(35) Tukker, A.; de Koning, A.; Wood, R.; Moll, S.; Bouwmeester, M. C. Price corrected domestic technology assumption. A method to assess pollution embodied in trade using primary official statistics only. Environ. Sci. Technol. 2013, 47 (4), 1775-1783.

(36) Weber, C. L.; Peters, G. P.; Guan, D.; Hubacek, K. The contribution of Chinese exports to climate change. Energy Policy 2008, 36 (9), 3572-3577.

(37) Zhao, H. Y.; Zhang, Q.; Guan, D. B.; Davis, S. J.; Liu, Z.; Huo, H.; Lin, J. T.; Liu, W. D.; He, K. B. Assessment of China's virtual air pollution transport embodied in trade by using a consumption-based emission inventory. Atmos. Chem. Phys. 2015, 15 (10), 5443-5456.

(38) Tukker, A.; Dietzenbacher, E. Global multiregional inputoutput frameworks: an introduction and outlook. Econ. Syst. Res. 2013, 25 (1), 1-19.

(39) Dietzenbacher, E.; Guilhoto, J.; Imori, D., The role of Brazilian regions in the global value chain. In $59^{\text {th }}$ Annual North American Meetings of the Regional Science Association International; Department of Economics, FEA-USP Working Paper: Ottawa, Canada, 2012.

(40) Faturay, F.; Lenzen, M.; Nugraha, K. A new sub-national multiregion input-output database for Indonesia. Econ. Syst. Res. 2017, 29 (2), 234-251.

(41) Cherubini, L.; Los, B. Regional employment patterns in a globalizing world: A tale of four Italies. Global value chains: new evidence and implications 2016, 213-235.

(42) White, D. J.; Hubacek, K.; Feng, K.; Sun, L.; Meng, B. The Water-Energy-Food Nexus in East Asia: A tele-connected value chain analysis using inter-regional input-output analysis. Appl. Energy 2018, $210,550-567$.

(43) Meng, B.; Yamano, N. Compilation of a regionally extended inter-country input-output table and its application to global value chain analyses. Journal of Economic Structures 2017, 6 (1), 23.

(44) Monsalve, F.; Ortiz, M.; Cadarso, M.-Á.; Gilles, E.; Zafrilla, J.; López, L.-A. Nesting a city input-output table in a multiregional framework: a case example with the city of Bogota. Journal of Economic Structures 2020, 9 (1), 8.

(45) Chen, G.; Wiedmann, T.; Wang, Y.; Hadjikakou, M. Transnational city carbon footprint networks - Exploring carbon links between Australian and Chinese cities. Appl. Energy 2016, 184, 1082-1092.

(46) Athanassiadis, A.; Christis, M.; Bouillard, P.; Vercalsteren, A.; Crawford, R. H.; Khan, A. Z. Comparing a territorial-based and a consumption-based approach to assess the local and global environmental performance of cities. J. Cleaner Prod. 2018, 173, 112-123.

(47) Meng, B.; Wang, Z.; Koopman, R. How Are Global Value Chains Fragmented and Extended in China's Domestic Production Networks?;
Institute of Developing Economies, Japan External Trade Organization (IDE-JETRO): Chiba-shi, Japan, 2013.

(48) Meng, B.; Zhang, Y.; Inomata, S. Compilation and applications of IDE-JETRO's international input-output tables. Econ. Syst. Res. 2013, 25 (1), 122-142.

(49) Inomata, S.; Meng, B. Compilation and Use of the 2005 Transnational Interregional Input-Output Tables for China, Japan and Korea; Institute of Developing Economies, Japan External Trade Organization (IDE-JETRO): Chiba-shi, Japan, 2013.

(50) de Koning, A.; Bruckner, M.; Lutter, S.; Wood, R.; Stadler, K.; Tukker, A. Effect of aggregation and disaggregation on embodied material use of products in input-output analysis. Ecol. Econ. 2015, 116, 289-299.

(51) Leontief, W. Environmental repercussions and the economic structure: An input-output approach. review of economics and statistics 1970, 52 (3), 262-271.

(52) Miller, R. E.; Blair, P. D. Input-Output Analysis: Foundations and Extensions. Cambridge University Press: Cambridge, 2009.

(53) Giljum, S.; Bruckner, M.; Martinez, A. Material footprint assessment in a global input-output framework. J. Ind. Ecol. 2015, 19 (5), 792-804.

(54) Liu, W.; Tang, Z.; Chen, J.; Yang, B. China's Interregional Input-Output Tables between 30 Provinces in 2010; China Statistics Press: Beijing, 2014.

(55) Stadler, K.; Wood, R.; Bulavskaya, T.; Södersten, C. J.; Simas, M.; Schmidt, S.; Usubiaga, A.; Acosta-Fernández, J.; Kuenen, J.; Bruckner, M.; et al. EXIOBASE 3: Developing a time series of detailed environmentally extended multi-regional input-output tables. J. Ind. Ecol. 2018, 22 (3), 502-515.

(56) Eurostat Economy-Wide Material Flow Accounts (EW-MFA): Compilation Guide 2013; Eurostat: Luxembourg, 2013.

(57) International Resource Panel. Global Material Flows Database; United Nations Environment Programme: Paris, 2017.

(58) International Resource Panel. Technical annex for Global Material Flows Database; United Nations Environment Programme: Paris, 2018.

(59) Zhu, S.; Yamano, N.; Cimper, A. Compilation of Bilateral Trade Database by Industry and End-Use Category; OECD Science, Technology and Industry Working Papers: Paris, 2011.

(60) Tukker, A.; de Koning, A.; Wood, R.; Hawkins, T.; Lutter, S.; Acosta, J.; Rueda Cantuche, J. M.; Bouwmeester, M.; Oosterhaven, J.; Drosdowski, T.; et al. EXIOPOL-development and illustrative analyses of a detailed global MR EE SUT/IOT. Econ. Syst. Res. 2013, 25 (1), 50-70.

(61) Bouwmeester, M. Algorithm Applied on the Full EXIOPOL SUT Data Set and Documentation Provided; RU Groningen. Groningen, Netherlands, 2011.

(62) Koopman, R.; Powers, W.; Wang, Z.; Wei, S.-J. Give Credit Where Credit Is Due: Tracing Value Added in Global Production Chains; National Bureau of Economic Research, 2010; pp 0898-2937.

(63) Södersten, C.-J.; Wood, R.; Wiedmann, T. The capital load of global material footprints. Resour. Conserv. Recycl. 2020, 158, 104811.

(64) Wiebe, K. S.; Lenzen, M. To RAS or not to RAS? What is the difference in outcomes in multi-regional input-output models? Econ. Syst. Res. 2016, 28 (3), 383-402.

(65) Jiang, X.; Chen, Q.; Guan, D.; Zhu, K.; Yang, C. Revisiting the Global Net Carbon Dioxide Emission Transfers by International Trade: The Impact of Trade Heterogeneity of China. J. Ind. Ecol. 2016, 20 (3), 506-514.

(66) National Bureau of Statistics of China. China Energy Statistics Yearbook; National Statistics Press: Beijing, 2011.

(67) Dietzenbacher, E.; Pei, J.; Yang, C. Trade, production fragmentation, and China's carbon dioxide emissions. Journal of Environmental Economics and Management 2012, 64 (1), 88-101. 